\title{
Charge Transfer Dynamics in Donor-Acceptor Complexes between a Conjugated Polymer and Fluorene Acceptors
}

Krompiec, M.P.; Pavelyev, V.G.; Parashchuk, O.D.; Krompiec, M.; Orekhova, T.V.; Perepichka, I.F.; van Loosdrecht, P.H.; Paraschuk, D.Y.; Pshenichnikov, M.S.

\section{Journal of Physical Chemistry C}

DOI:

$10.1021 / \mathrm{jp} 510543 \mathrm{c}$

Published: 19/11/2014

Peer reviewed version

Cyswllt i'r cyhoeddiad / Link to publication

Dyfyniad o'r fersiwn a gyhoeddwyd / Citation for published version (APA):

Krompiec, M. P., Pavelyev, V. G., Parashchuk, O. D., Krompiec, M., Orekhova, T. V.,

Perepichka, I. F., van Loosdrecht, P. H., Paraschuk, D. Y., \& Pshenichnikov, M. S. (2014).

Charge Transfer Dynamics in Donor-Acceptor Complexes between a Conjugated Polymer and Fluorene Acceptors. Journal of Physical Chemistry C, 51(118), 30291-30301.

https://doi.org/10.1021/jp510543c

\footnotetext{
Hawliau Cyffredinol / General rights

Copyright and moral rights for the publications made accessible in the public portal are retained by the authors and/or other copyright owners and it is a condition of accessing publications that users recognise and abide by the legal requirements associated with these rights.

- Users may download and print one copy of any publication from the public portal for the purpose of private study or research.

- You may not further distribute the material or use it for any profit-making activity or commercial gain

- You may freely distribute the URL identifying the publication in the public portal ?
}

Take down policy

If you believe that this document breaches copyright please contact us providing details, and we will remove access to the work immediately and investigate your claim. 
This document is confidential and is proprietary to the American Chemical Society and its authors. Do not copy or disclose without written permission. If you have received this item in error, notify the sender and delete all copies.

\section{Charge Transfer Dynamics in Donor-Acceptor Complexes between a Conjugated Polymer and Fluorene Acceptors}

\begin{tabular}{|r|l|}
\hline Journal: & The Journal of Physical Chemistry \\
\hline Manuscript ID: & jp-2014-10543c.R1 \\
\hline Manuscript Type: & Article \\
\hline Date Submitted by the Author: & n/a \\
\hline Complete List of Authors: & $\begin{array}{l}\text { Pavelyev, Vlad; Zernike Institute for Advanced Materials, } \\
\text { Parashchuk, Olga; Lomonosov Moscow State University, Physics } \\
\text { Krompiec, Michal; Merck Chemicals Ltd. , Chilworth Technical Centre } \\
\text { Orekhova, Tatyana; L. M. Litvinenko Institute of Physical Organic and Coal } \\
\text { Chemistry, National Academy of Sciences of Ukraine } \\
\text { Perepichka, Igor; Bangor University, School of Chemistry } \\
\text { van Loosdrecht, Paul; University of Groningen, Zernike Institute for } \\
\text { Advanced Materials } \\
\text { Paraschuk, Dmitry; Moscow State University, Faculty of Physics } \\
\text { Pshenichnikov, Maxim; Zernike Institute for Advanced Materials, University } \\
\text { of Groningen }\end{array}$ \\
\hline
\end{tabular}




\title{
Charge Transfer Dynamics in Donor-Acceptor
}

\section{Complexes between a Conjugated Polymer and}

\section{Fluorene Acceptors}

\author{
Vlad G. Pavelyev, ${ }^{1}$ Olga D. Parashchuk, ${ }^{2}$ Michal Krompiec, ${ }^{3,+}$ Tatyana V. Orekhova, ${ }^{4}$ Igor F. \\ Perepichka, ${ }^{3, *}$ Paul H. M. van Loosdrecht, ${ }^{1, \#}$ Dmitry Yu. Paraschuk, ${ }^{2, *}$ and Maxim S. Pshenichnikov ${ }^{1, *}$ \\ ${ }^{1}$ Zernike Institute for Advanced Materials, University of Groningen, Nijenborgh 4, 9747 AG \\ Groningen, The Netherlands \\ ${ }^{2}$ Faculty of Physics and International Laser Center, Lomonosov Moscow State University, Leninskie \\ Gory, 119991 Moscow, Russia \\ ${ }^{3}$ School of Chemistry, Bangor University, Deiniol Road, Bangor LL57 2UW, United Kingdom \\ ${ }^{4}$ L. M. Litvinenko Institute of Physical Organic and Coal Chemistry, National Academy of Sciences of \\ Ukraine, R. Luxemburg Street 70, Donetsk 83114, Ukraine
}

\begin{abstract}
We report on ground and excited state charge transfer in charge-transfer complexes in films formed between a semiconducting polymer, MEH-PPV (poly[2-methoxy-5-(2'-ethylhexyloxy)1,4-phenylene vinylene]), and a series of fluorene electron acceptors. The latter were designed to vary systematically the electron affinity (EA) over $\sim 1.5 \mathrm{eV}$ by attachment of various electron withdrawing groups to the fluorene core. The EAs of the acceptors are determined by cyclic voltammetry and
\end{abstract}


compared with those from Density Functional Theory calculations. The charge transfer dynamics are studied using an ultrafast visible-pump - IR-probe photoinduced absorption technique. We demonstrate that the acceptor EA is the key - but not the only - parameter that governs charge recombination rates that scale exponentially with the acceptor EA. From the time-resolved data we deduced a model that describes charge dynamics for acceptors with low and high EAs. The two opposite trends - higher acceptor EA increases the driving force for charge separation but also inevitably increases the rate of undesirable charge recombination - should be carefully counterbalanced in designing of novel polymer-fullerene bulk heterojunctions.

KEYWORDS: charge-transfer complex, electron affinity, ultrafast spectroscopy, polaron dynamics, polymer-acceptor blends. 


\section{INTRODUCTION}

The electronic ground state of a molecular charge-transfer complex (CTC) is formed by the transfer of a fraction of the electron charge between the non-covalently bound molecular entities, the donor and the acceptor. CTCs and the very process of electron transfer lay at the heart of many photoinduced processes in physics, chemistry, and biology. According to the Mulliken model, ${ }^{1,2}$ the amount of the donor-acceptor charge transfer in the CTC ground state is mainly controlled by the difference between the donor ionization potential and the acceptor electron affinity (EA) or in first approximation by the energy difference between the acceptor lowest unoccupied molecular orbital (LUMO) and the donor highest occupied molecular orbital (HOMO), also known as the effective HOMO-LUMO gap. ${ }^{3}$

Upon optical excitation of the Mulliken-type CTCs, a major part of the electron density is transferred from the donor to the acceptor almost instantaneously while the back electron transfer, i.e. charge recombination, occurs within a finite time span. ${ }^{4,5}$ The early studies on dynamics of small-molecule CTCs in solutions ${ }^{6,7}$ demonstrated that the driving force for geminate charge recombination is mainly determined by the acceptor EA. The charge recombination rate was shown to scale exponentially with the acceptor EA, while some deviations were attributed to the reorganization energy variations. ${ }^{6}$

In recent years, a new kind of Mulliken-type CTCs involving conjugated polymers as donors has been identified in a variety of polymer-acceptor blends. ${ }^{8-12}$ A number of unusual properties makes the polymer-based CTCs especially fascinating in comparison to their small-molecule counterparts. Planarization of the polymer chains ${ }^{13}$ and formation of crystalline domains ${ }^{14}$ are but two examples. Such properties are closely related to charge delocalization over conjugated polymer chains (nonexisting in small-molecule CTCs) so that the electron density from several repeating units of the polymer is transferred to an acceptor molecule. ${ }^{13,15}$

Ground-state CTCs have also been observed in conjugated polymer-fullerene blends ${ }^{16}$ although their absorption is extremely weak ${ }^{17-19}$, partially because CTCs are formed only near the donor-acceptor interface which volume share is minute. In contrast, in polymer-acceptor blends with pronounced 
ground-state charge transfer, a CTC is formed almost per each conjugated segment so that exciton diffusion and other concurrent processes (e.g., generation of triplets) do not affect the photophysics. As a result, optical excitation leads to immediate formation of a charge-separated state whose charge relaxation dynamics can be readily monitored. ${ }^{20,21}$ Furthermore, the new generation of low bandgap conjugated polymers for organic photovoltaics (OPV), which has already demonstrated the highest

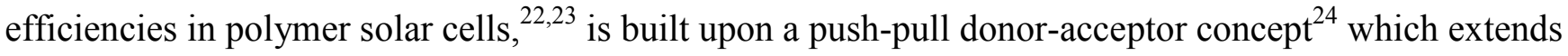
the light absorption into the red region of the solar spectrum. This is highly reminiscent of Mullikentype CTC absorption, the difference in the charge-transfer state origin (i.e. covalently linked alternating electron donating and electron accepting monomer units in the polymer backbone $v s$. non-covalently bonded polymer and small-molecule acceptor) notwithstanding.

Insofar, the effect of an acceptor EA on the charge recombination dynamics in conjugated polymer CTCs has only been studied for two commercially-available acceptors of different molecular structures. $^{20,21}$ As a result, no functional dependences of the charge recombination rates as a function of acceptor EA could have emerged, in sharp contrast to the case of small-molecule CTCs in solutions. ${ }^{4-7}$ This calls for a systematic study of charge recombination dynamics in conjugated polymer based CTCs where the acceptor EAs are varied in a controlled and predictable way with as small as possible alternations of the acceptor molecular structure.

In this paper, we report on how the acceptor EA controls the charge recombination dynamics in CTCs between an archetypical conjugated polymer donor MEH-PPV (poly[2-methoxy-5-(2'ethylhexyloxy)-1,4-phenylene vinylene] $)^{25}$ and a family of small molecular acceptors (Figure 1). A series of fluorene acceptors with a range of EAs was designed, synthesized and characterized by cyclic voltammetry and Density Functional Theory calculations. The CTC excited state dynamics were studied via generation and recombination of photoinduced charges employing ultrafast visible-pump IR-probe photo-induced absorption spectroscopy. We show that the recombination rate scales exponentially with the acceptor EA, similar to the earlier observations for small-molecule CTCs in 
solution. ${ }^{6,26}$ Finally, the anisotropy dynamics suggest that separated charges in most of the blends remain highly spatially-localized, in sharp contrast to the case of the pristine polymer.

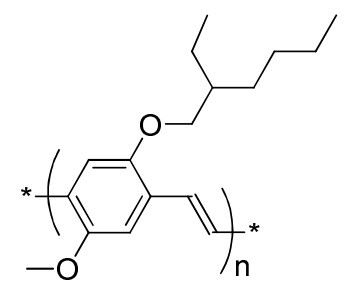

MEH-PPV

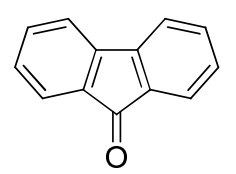

Fon

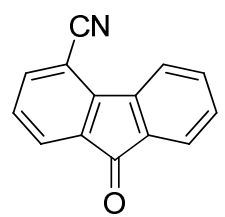

4CN-Fon

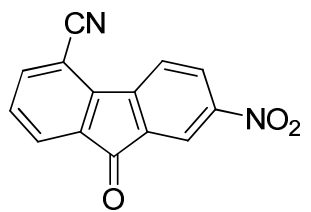

4CN-NFon

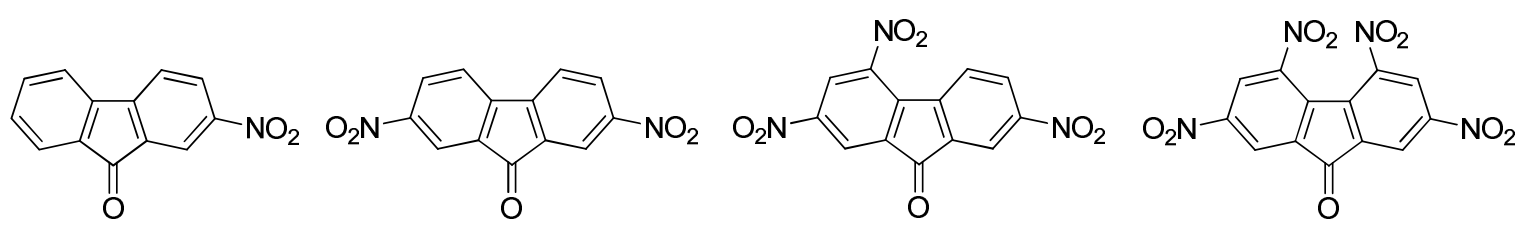

NFon

DNFon

TNFon

TeNFon
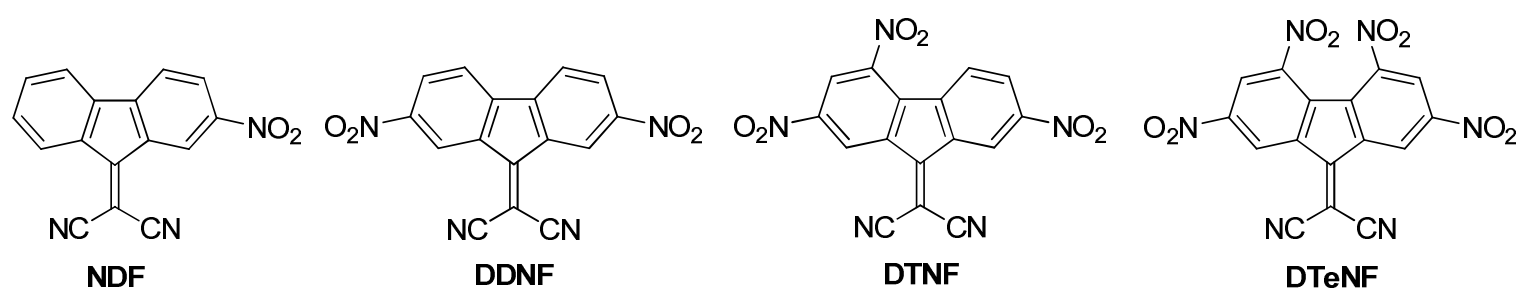

Figure 1. Structures of the MEH-PPV polymer (upper left) and the studied series of fluorene electron acceptors. Abbreviations of the latter are shown in bold.

\section{EXPERIMENTAL}

\subsection{Samples}

Fluorenone (Fon) and 2,7-dinitrofluorenone (DNFon) have been purchased from Sigma-Aldrich and used without further purification. Details of the synthesis of fluorene acceptors 2-nitrofluorenone (NFon), 2,4,7-trinitrofluorenone (TNFon), 2,4,5,7-tetranitrofluorenone (TeNFon), 2-nitro-9dicyanomethylenefluorene (NDF), 2,7-dinitro-9-dicyanomethylenefluorene (DDNF), 2,4,7-trinitro-9- 
dicyanomethylenefluorene (DTNF), 2,4,5,7-tetranitro-9-dicyanomethylenefluorene (DTeNF), 4cyanofluorenone (4CN-Fon), and 2-nitro-5-cyanofluorenone (4CN-NFon) and their characterizations are given in the Supporting Information (see "Synthesis of fluorene acceptors" section and Figs.S1-S16 for NMR spectra). Absorption spectra of the acceptors in chlorobenzene (Fig.S17) are situated in the blue-UV region below $450 \mathrm{~nm}$; no signs of aggregation at concentrations up to $2 \mathrm{~g} \cdot \mathrm{L}^{-1}$ were found.

MEH-PPV was chosen as a donor since it is known to readily form a ground-state CTC with fluorene electron acceptors. ${ }^{13,27}$ MEH-PPV (Sigma-Aldrich, $\left.M_{\mathrm{n}}=86000, M_{\mathrm{w}}=420000\right)$ and fluorene acceptors were dissolved separately in chlorobenzene at a concentration of $2 \mathrm{~g} \cdot \mathrm{L}^{-1}$. The solutions were placed into an ultrasonic bath for 15 minutes at $22^{\circ} \mathrm{C}$ and then stirred with a magnetic stirrer for $\sim 6$ hours at $50^{\circ} \mathrm{C}$. Their blends were prepared by mixing the solutions of MEH-PPV and an acceptor with a molar ratio of 1:0.3 per polymer repeat unit. Further increase of the acceptor concentration in the blends led to phase segregation with loss of sample optical quality. ${ }^{28}$

Films were prepared by drop casting of MEH-PPV/acceptor solution onto a $150 \mu \mathrm{m}$ thick microscope cover slide with subsequent drying for 8 hours in an air atmosphere at $22^{\circ} \mathrm{C}$. The resulted optical density of the samples did not exceed $\sim 1.5$ at their maxima. The solution of MEH-PPV with the highest EA acceptor, DTeNF, exhibited strong phase segregation and CTC precipitation, and therefore was not used in the optical experiments. All experiments were performed at ambient conditions; no sample degradation was observed during the experiments.

\subsection{Cyclic voltammetry}

Electrochemical experiments were carried out using an Autolab PGSTAT-302N potentiostatgalvanostat. Cyclic voltammetry $(\mathrm{CV})$ measurements were performed in a three-electrode cell equipped with a platinum disk $(\mathrm{d}=1.6 \mathrm{~mm})$ as the working electrode, platinum wire as a counter electrode and a non-aqueous $\mathrm{Ag} / \mathrm{Ag}^{+}$reference electrode (0.01 $\mathrm{M} \mathrm{AgNO}_{3}$ and $0.1 \mathrm{M} \mathrm{Bu}_{4} \mathrm{NPF}_{6}$ in $\left.\mathrm{MeCN}\right)$. Cyclic voltammograms were recorded at room temperature in dry acetonitrile, deoxygenated by bubbling with 
argon gas, with $0.1 \mathrm{M} \mathrm{Bu}_{4} \mathrm{NPF}_{6}$ as supporting electrolyte, with ohmic drop compensation. The potentials were corrected with ferrocene/ferrocenium redox pair $\left(\mathrm{Fc} / \mathrm{Fc}^{+}\right)$as an internal standard, which showed the potential of $0.090-0.100 \mathrm{~V}$ versus the used reference electrode in our conditions. LUMO energies $\left(\mathrm{E}_{L U M O}^{C V}\right)$ were estimated from the half-wave reduction potentials using the widely used relation introduced by Pommerehne et al. ${ }^{29}$ (see also Ref. 30$): E_{L U M O}^{C V}[\mathrm{eV}]=-\left(4.8-E_{1 / 2}^{r e d}\right.$ ), where -4.8 $\mathrm{eV}$ is the potential of $\mathrm{Fc} / \mathrm{Fc}^{+}$redox pair versus Fermi level. MEH-PPV HOMO and LUMO energies of -5.0 and $-2.8 \mathrm{eV}$, respectively, were taken from the electrochemical data in Ref. 31 .

\subsection{Computational procedures}

DFT computations of the geometries of the studied fluorene electron acceptors were carried out with the Gaussian $09^{32}$ package of programs by using Pople's 6-31G split valence basis set supplemented by d-polarization functions for heavy atoms and with diffusion functions on them. Becke's three-parameter hybrid exchange functional ${ }^{33,34}$ with the Lee-Yang-Parr gradient-corrected correlation functional $(B 3 L Y P)^{35}$ were employed. The restricted Hartree-Fock formalism was used for calculations of neutral molecules whereas the unrestricted HF formalism was used for the calculation of radical anion states. No constraints were used and all structures were free to optimize in an acetonitrile solution using the polarizable continuum model $(\mathrm{PCM}) .{ }^{36-40}$ Thus, the geometries were optimized at the B3LYP/6$31+\mathrm{G}(\mathrm{d})$ level of theory and the electronic structures were calculated at the same level of theory. From these calculations on the neutral molecules (in acetonitrile) we estimated the frontier orbital energy levels, $E_{L U M O}^{D F T}$ and $E_{H O M O}^{D F T}$. Vertical electron affinities $\left(E A_{V}^{D F T}\right)$ were computed as the difference between the total energies of the optimized neutral state $E_{\text {total }}^{\mathrm{OptN}}$ and the radical anion at the frozen geometry of the neutral, $E_{\text {total }}^{\mathrm{RAF}}$ :

$$
E A_{V}^{D F T}=E_{\text {total }}^{\mathrm{OptN}}-E_{\text {total }}^{\mathrm{RA} F}
$$


Adiabatic electron affinities $\left(E A_{A}^{D F T}\right)$ were calculated as the difference in total energies between the optimized geometries of the neutral $E_{\text {total }}^{\text {OptN }}$ and radical anion $E_{\text {total }}^{\text {RA_Opt }}$ states, including zero point energies corrections $Z P E^{\mathrm{N}}$ and $Z P E^{\mathrm{RA}}$ for the two state, respectively:

$$
E A_{A}^{D F T}=E_{\text {total }}^{\mathrm{OptN}}-E_{\text {total }}^{\mathrm{RA} \mathrm{Opt}}+Z P E^{\mathrm{N}}-Z P E^{\mathrm{RA}}
$$

\subsection{Ultrafast spectroscopy experiments}

The dynamics of photogenerated charges in selected materials have been explored with a photoinduced absorption (PIA) technique, where allows monitoring the time evolution of photoinduced charges. The method is based on the fact that a charge (a hole) created on a polymer molecule induces absorption bands in the polymer optical gap in the IR range. ${ }^{41}$ These bands called low energy (LE) and high energy (HE) polaron bands ${ }^{42}$ are situated for the MEH-PPV polymer at $\sim 3500$ and $\sim 10000 \mathrm{~cm}^{-1}$, respectively. ${ }^{20,43}$ The LE band is more suitable as a reporter of charge concentration because it is not contaminated by other responses, like electro absorption, stimulated emission etc. which allows for a background free measurement. ${ }^{20,} 44$ In the PIA technique, two pulses are applied: the first one photogenerates the charges and the second one probes the charge concentration by monitoring induced absorption in the IR spectral region. For the aforementioned reasons, the probe wavelength was set at $2.94 \mu \mathrm{m}$, i.e. near the LE polaron absorption peak (see Ref. 20 for the polaron absorption spectrum).

Briefly, the PIA experiments were performed with a home-built 1kHz Ti:Sapphire multipass amplifies laser system that pumps an IR optical parametrical oscillator (OPO) and a nonlinear optical parametrical amplifier (NOPA). The NOPA generated $\sim 30 \mathrm{fs}, \sim 3 \mathrm{~nJ}$ pulses in the visible range (500$750 \mathrm{~nm}$ ). The power density at the sample position did not exceed $800 \mathrm{~nJ} / \mathrm{cm}^{2}$ to ensure a linear excitation regime and absence of bimolecular (non-geminate) recombination. The IR OPO was optimized to provide $\sim 70$ fs pulses at $\sim 3400 \mathrm{~cm}^{-1}$ (near the center of the LE polaron absorption band). To realize polarization-sensitive measurements, the polarization of the IR probe beam was rotated by 
$45^{\circ}$ with respect to the polarization of the visible pump beam. Parallel and perpendicular components of the probe beam were selected after the sample by grid-wire polarizers and detected by two InSb photodiodes. The photodiode signals were processed by lock-in amplifiers synchronized to a mechanical chopper $(500 \mathrm{~Hz})$ inserted into the visible pump beam. To obtain relative changes in the transmission $\Delta \mathrm{T}$, the differential pump-on, pump-off signal $\Delta \mathrm{I}$ from the lock-ins were normalized to the intensity I of the IR beam transmitted through the sample:

$\Delta T=\frac{\Delta I}{I}$

To calculate the isotropic $\Delta T_{I s o}(t)$ and anisotropic $r(t)$ transients the standard expressions $(4,5)^{45}$ were used:

$$
\begin{aligned}
& \Delta T_{\text {Iso }}(t)=\frac{\Delta T_{\|}(t)+2 \cdot \Delta T_{\perp}(t)}{3} \\
& r(t)=\frac{\Delta T_{\|}(t)-\Delta T_{\perp}(t)}{3 \cdot \Delta T_{I s o}(t)}
\end{aligned}
$$

where $\Delta T_{\perp}(t)$ and $\Delta T_{\|}(t)$ are relative transmission changes of the perpendicular and parallel components of the probe signal. All data were obtained under ambient conditions at room temperature.

\section{RESULTS AND DISCUSSION}

\subsection{Fluorene acceptors design}

The acceptor EA engineering was achieved by attaching a number of different electron-withdrawing functional groups to the fluorene core: from one to four nitro groups or/and cyano group at the benzene rings, as well as using carbonyl oxygen or dicyanomethylene groups at the C-9 bridged atom of the fluorene moiety (Figure 1). While the effect of introducing several electron withdrawing groups in the fluorene moiety is not exactly additive (especially in the case nitro groups introduced at different positions of the fluorene moiety), analysis of previous spectroscopic and electrochemical studies on 
different electron acceptors of the fluorene series allows for making such generalizations. The introduction of an $\mathrm{NO}_{2}$ group in substituted fluorenes increases the EA of the fluorene molecule by $\sim 0.2-0.3 \mathrm{eV}$ while replacement of oxygen in the carbonyl group by the dicyanomethylene fragment increases the EA by $\sim 0.35-0.45 \mathrm{eV} .{ }^{46-52}$ Therefore, with the structural variations of a selected series of fluorene acceptors presented in Figure 1, the LUMO energy levels can be tuned by $\sim 1.5 \mathrm{eV}$.

\subsection{Cyclic Voltammetry}

To estimate the LUMO energy levels of fluorene electron studied acceptors, their electrochemical reduction was studied by cyclic voltammetry $(\mathrm{CV})$ in dry acetonitrile, with a common three electrode scheme using $\mathrm{Fc} / \mathrm{Fc}^{+}$as an internal reference. Most of the studied acceptors showed two (or even three) reversible redox waves in acetonitrile solution to form stable radical anion and dianion species (in $\mathrm{CV}$ timescale), respectively, except for the lowest EA acceptors Fon, 4CN-Fon and NFon, which showed only the first redox wave to be reversible (Figure 2). An increase of the number of nitro groups results in progressive shift of redox potentials into the positive potential region, and further pronounced shifts are observed on replacement of $\mathrm{O}$ by $\mathrm{C}(\mathrm{CN})_{2}$ groups. The first and second half-wave reduction potentials, $E_{1 / 2}^{\text {red } 1}$ and $\mathrm{E}_{1 / 2}^{\text {red2 }}$, are collated in Table 1 and have been used to estimate the LUMO energy levels of acceptors ( $E_{C V}^{L U M O}$, Table 1, Fig. 3), assuming an Fc potential of $-4.8 \mathrm{eV}$ versus Fermi level. The data for $E_{C V}^{L U M O}$ presented in Table 1 indicate that for both series (fluorenones and 9dicyanomethylenefluorenes) each nitro group incrementally decreases the LUMO energy of the acceptors by $\sim 0.22-0.27 \mathrm{eV}$, except for the weakest acceptor, unsubstituted fluorenone Fon, in which case an insertion of first $\mathrm{NO}_{2}$ group (NFon) results in a decrease of the LUMO energy by $0.34 \mathrm{eV}$. Replacement of oxygen by a dicyanomethylene group in acceptors decreases their LUMO energies by 0.41-0.46 eV. These data are in good agreement with the observed linear relationships of first reduction potentials, ${ }^{53}$ as well as with intramolecular charge transfer energies ${ }^{54}$ in fluorene acceptors by 
Hammett-type correlations. The EAs of the studied acceptors estimated from the electrochemical experiments, were assigned as $E A^{C V}=-E_{L U M O}^{C V}$, in accordance with Koopman's theorem.
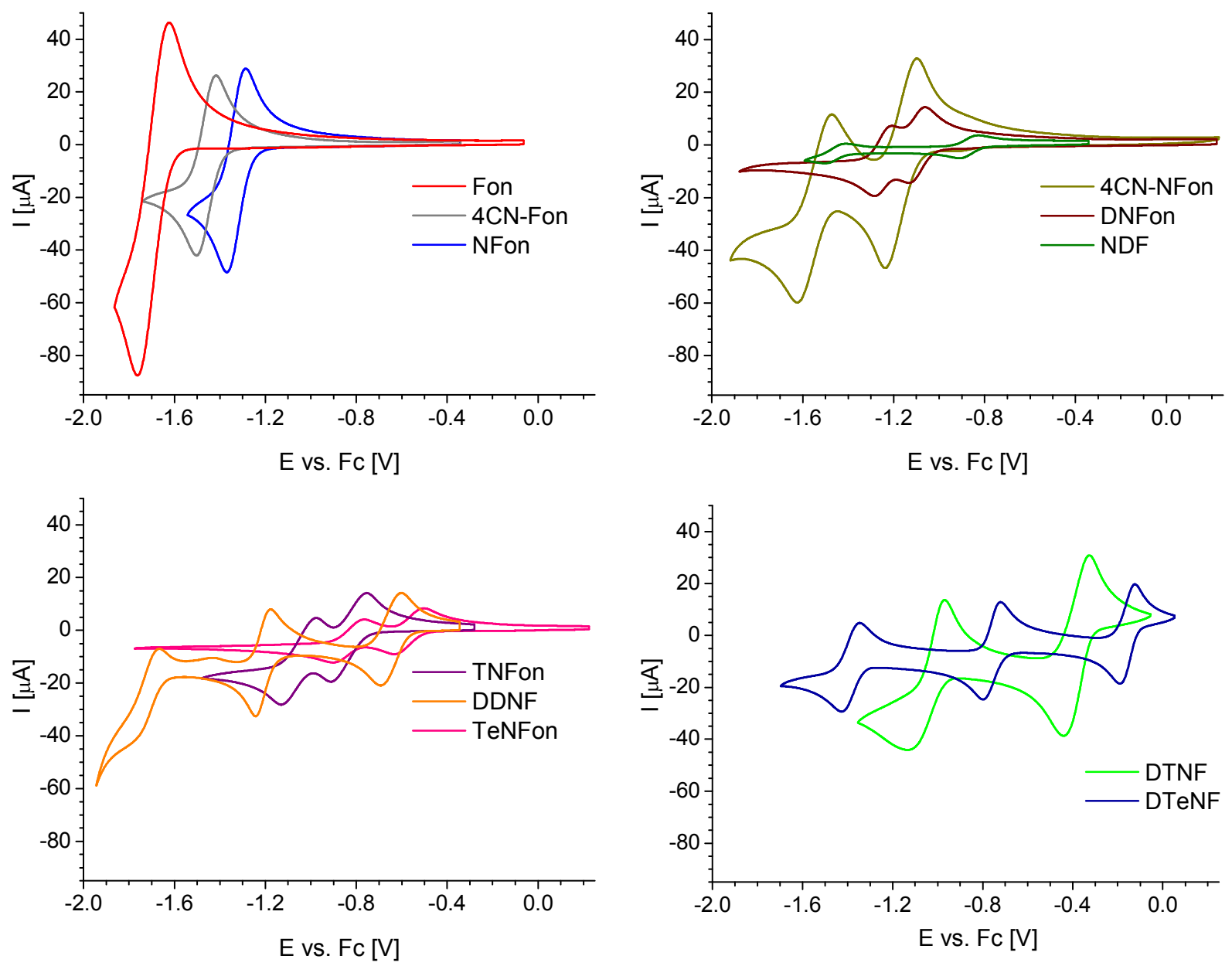

Figure 2. Cyclic voltammograms of fluorene acceptors in deoxygenated acetonitrile, supporting electrolyte $0.1 \mathrm{M} \mathrm{Bu}_{4} \mathrm{NPF}_{6}$, scan rate $100 \mathrm{mV} \mathrm{s}^{-1}$. 
Table 1. Reduction CV potentials and calculated energy levels of fluorene acceptors

\begin{tabular}{llllllll}
\hline Compound & $\begin{array}{l}E_{1 / 2}^{\text {red1 }} \\
{[\mathrm{V}]^{a}}\end{array}$ & $\begin{array}{c}E_{1 / 2}^{\text {red2 }} \\
{[\mathrm{V}]^{a}}\end{array}$ & $\begin{array}{c}E_{L U M O}^{C V} \\
{[\mathrm{eV}]^{b}}\end{array}$ & $\begin{array}{c}E_{L U M O}^{D F T} \\
{[\mathrm{eV}]^{c}}\end{array}$ & $\begin{array}{c}E_{H O M O}^{D F T} \\
{[\mathrm{eV}]^{c}}\end{array}$ & $\begin{array}{c}E A_{V}^{D F T} \\
{[\mathrm{eV}]^{d}}\end{array}$ & $\begin{array}{c}E A_{A}^{D F T} \\
{[\mathrm{eV}]^{e}}\end{array}$ \\
\hline Fon & -1.669 & - & -3.131 & -2.781 & -6.534 & 2.891 & 3.140 \\
4CN-Fon & -1.460 & - & -3.340 & -3.013 & -6.847 & 3.120 & 3.379 \\
4CN-NFon & -1.159 & -1.516 & -3.641 & -3.555 & -7.292 & 3.647 & 3.910 \\
NFon & -1.328 & - & -3.472 & -3.372 & -6.966 & 3.459 & 3.730 \\
DNFon & -1.098 & -1.245 & -3.702 & -3.749 & -7.435 & 3.839 & 4.087 \\
TNFon & -0.839 & -1.054 & -3.961 & -4.045 & -7.789 & 4.142 & 4.393 \\
TeNFon & -0.564 & -0.814 & -4.236 & -4.377 & -8.136 & 4.478 & 4.725 \\
NDF & -0.869 & -1.456 & -3.931 & -3.768 & -7.041 & 3.891 & 4.081 \\
DDNF & -0.648 & -1.210 & -4.152 & -4.045 & -7.492 & 4.165 & 4.356 \\
DTNF & -0.383 & -1.050 & -4.417 & -4.302 & -7.815 & 4.420 & 4.621 \\
DTeNF & -0.157 & -0.760 & -4.643 & -4.591 & -8.074 & 4.710 & 4.869 \\
\hline
\end{tabular}

${ }^{a}$ The first and second reduction half-wave potentials in acetonitrile versus $\mathrm{Fc} / \mathrm{Fc}^{+}$, calculated as averages of anodic and cathodic peak potentials from cyclic voltammetry. ${ }^{b}$ LUMO energy levels from $\mathrm{CV}$ experiments: $E_{L U M O}^{C V}=4.8-E_{1 / 2}^{r e d 1} \cdot{ }^{c} \mathrm{HOMO}$ and LUMO energy levels from B3LYP/6-31+G(d) calculations in acetonitrile. ${ }^{d}$ Vertical electron affinities of acceptors from B3LYP/6-31+G(d) calculations in acetonitrile (see eq. 1). ${ }^{e}$ Adiabatic electron affinities of acceptors from B3LYP/6$31+\mathrm{G}(\mathrm{d})$ calculations in acetonitrile (see eq. 2 ).

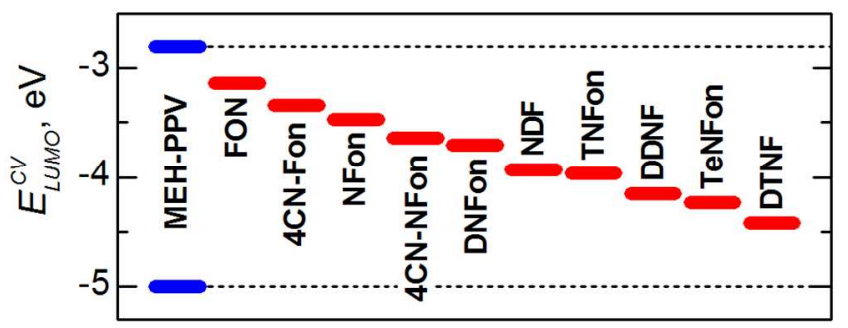

Figure 3. Positions of the LUMO energy levels $\left(E_{L U M O}^{C V}\right)$ of fluorene electron acceptors from $\mathrm{CV}$ experiments (red blocks). MEH-PPV HOMO and LUMO energies (blue blocks) are also shown for comparison. 


\subsection{DFT Computational Studies}

DFT computations have been performed at B3LYP/6-31+G(d) level of theory for both geometry optimizations and calculations of electronic structures of neutral acceptors and their radical anions. The effect of the solvent (acetonitrile) was incorporated using the polarizable continuum model (PCM) to match the results with CV measurements in this solvent. Kohn-Sham frontier orbital energies for neutral acceptors, $E_{H O M O}^{D F T}$ and $E_{L U M O}^{D F T}$, are collated in Table 1 (more details on B3LYP/6-31+G(d) level of theory calculations are given in Supporting Information, Table S1). Orbital energy diagrams together with HOMO and LUMO orbital coefficients of the fluorene acceptors obtained from B3LYP/6$31+\mathrm{G}(\mathrm{d})$ calculations in acetonitrile are given in the SI (Figure S18 and Table S2). It is evident that nitro groups incrementally decrease the LUMO energy levels for both fluorenone and 9dicyanomethylene series of acceptors (Figure S18), and while their effect is nor fully additive, the trend is clear and in general reproduces well the observations of $\mathrm{CV}$ experiments. Both nitro groups and dicyanomethylene fragment are substantially involved in LUMO delocalization, with a more pronounced effect for the $\mathrm{NO}_{2}$ groups in positions 2,7- as compared to positions 4,5-. Cyano groups in the benzene ring are very weakly involved in the LUMO delocalization (Figure 4, Table S2). The lower degree of LUMO delocalization over the 4,5-nitrogroups is partially due to a steric effect. According to single crystal X-ray data for various fluorene acceptors and their CTC, this results in rotation of $\mathrm{NO}_{2}$ around the $\mathrm{C}-\mathrm{N}$ bond to form dihedral angles with the fluorene plane (in general, $30-50^{\circ}$ and $3-10^{\circ}$, for nitrogroups in positions 4,5- and 2,7-, respectively. ${ }^{48-53,55-60}$ 


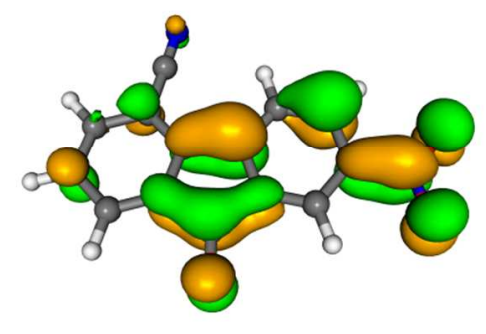

4CN-Fon $\left(E_{L U M O}^{D F T}=-3.56 \mathrm{eV}\right)$

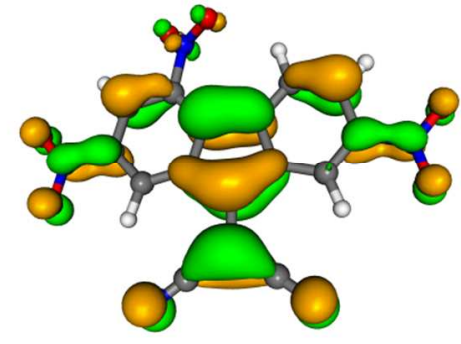

DTNF $\left(E_{L U M O}^{D F T}=-4.30 \mathrm{eV}\right)$

Figure 4. LUMO orbital coefficients for two representative fluorene acceptors from B3LYP/6-31+G(d) calculations in acetonitrile (for others, see Table S2)

In the DFT calculations, EAs are sometimes approximated by the LUMO energies $\left(\mathrm{EA}=-E^{\mathrm{LUMO}}\right)$ in accordance with DFT-Koopman's theorem. In addition to such estimation, we also calculated vertical and adiabatic electron affinities, $E A_{V}^{D F T}$ and $E A_{A}^{D F T}$ (Table 1). Both vertical and adiabatic EA values are in excellent linear relationship with the computed $E_{L U M O}^{D F T}$ energies, while better coincidence in absolute values is observed with the vertical ionization potentials, $E A_{V}^{D F T}$ (average deviations of ca.$0.1 \mathrm{eV}$, Figure 5 and SI, Figures S19 and S20). Comparison of the DFT data with CV experiments indicates that $E_{L U M O}^{D F T}$ and $E A_{V}^{D F T}$ show reasonably good linear correlations with the experimental $E_{L U M O}^{C V}$ values obtained from the cyclic voltammetry experiments, while for $E A_{A}^{D F T}$ the deviations are somewhat larger (Figure 5). In all the cases, the slopes are slightly higher than unity and increased positive deviations are observed for weaker acceptors Fon and 4CN-Fon, implying an underestimation of the EA by the DFT calculations. Small deviations from linear dependence between the CV data and computational estimations of orbital energies are partially due to the known fact of overestimation of conjugation by hybrid functionals ${ }^{61-65}$ affecting the computed LUMO energies as well as adiabatic EA values. Yet, reasonably good linear correlations between the experiments and the theory allow using computational methods in the design of fluorene acceptors with predictable EAs. Therefore, in the following we will use $-E_{L U M O}^{C V}$ as the acceptor EA. 


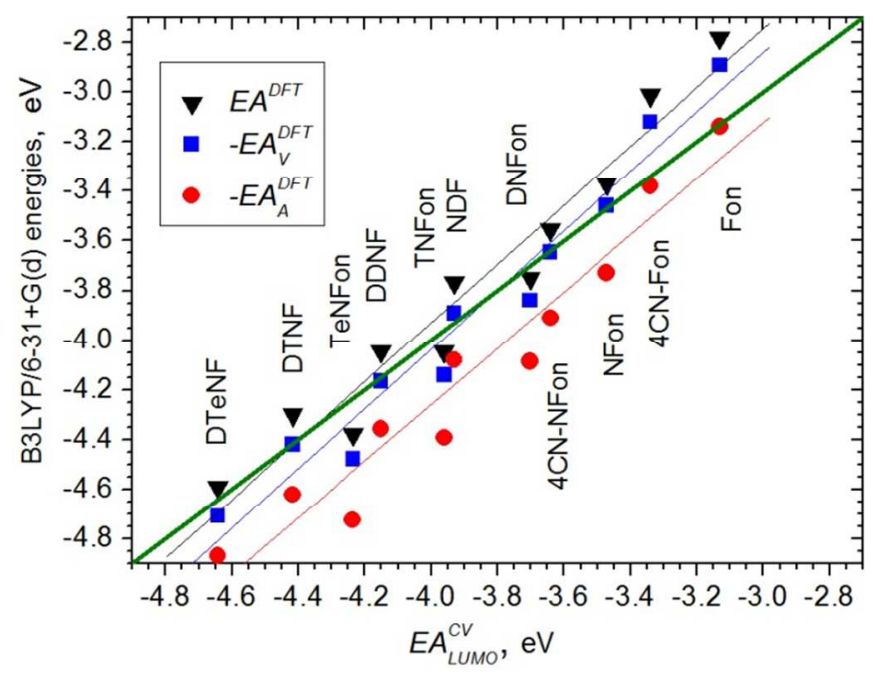

Figure 5. Comparison of experimental and calculated B3LYP/6-31+G(d) LUMO energy levels (ionization potentials) for the studied electron acceptors. Green line represents a bisection of equal energies between the axes (as such, the best quantitative coincidence with experimental data is for $\mathrm{EA}_{A}^{D F T}$ calculated values). Solid lines show linear fits to the respective data sets.

\subsection{Steady-State Absorption}

Figure 6a plots optical absorption spectra of the MEH-PPV:acceptor blends. For the sake of simplicity, the blends are named after the respective acceptor. With increase of the acceptor EA, i.e. with lowering of the effective HOMO-LUMO energy gap, the blends show characteristic signatures of a ground-state polymer:acceptor CTC previously identified for MEH-PPV:TNFon blends. ${ }^{8-11,13}$ First, an absorption tail begins to form in the polymer bandgap, i.e. at wavelengths longer than $600 \mathrm{~nm}$ (Figure 6b). Second, the absorption maximum is progressively shifted to the red (Figure 6a) for acceptors with EA higher than that of $\mathbf{4 C N}-\mathbf{N F o n}$. This indicates that the majority of the conjugated chains are involved in the CTC. ${ }^{13}$ For acceptors with high EA, an additional CTC absorption band is formed (most clearly seen for TeNFon), in accordance with the Mulliken model which predicts that the CTC absorption should be progressively red-shifted with increasing of the acceptor EA. 

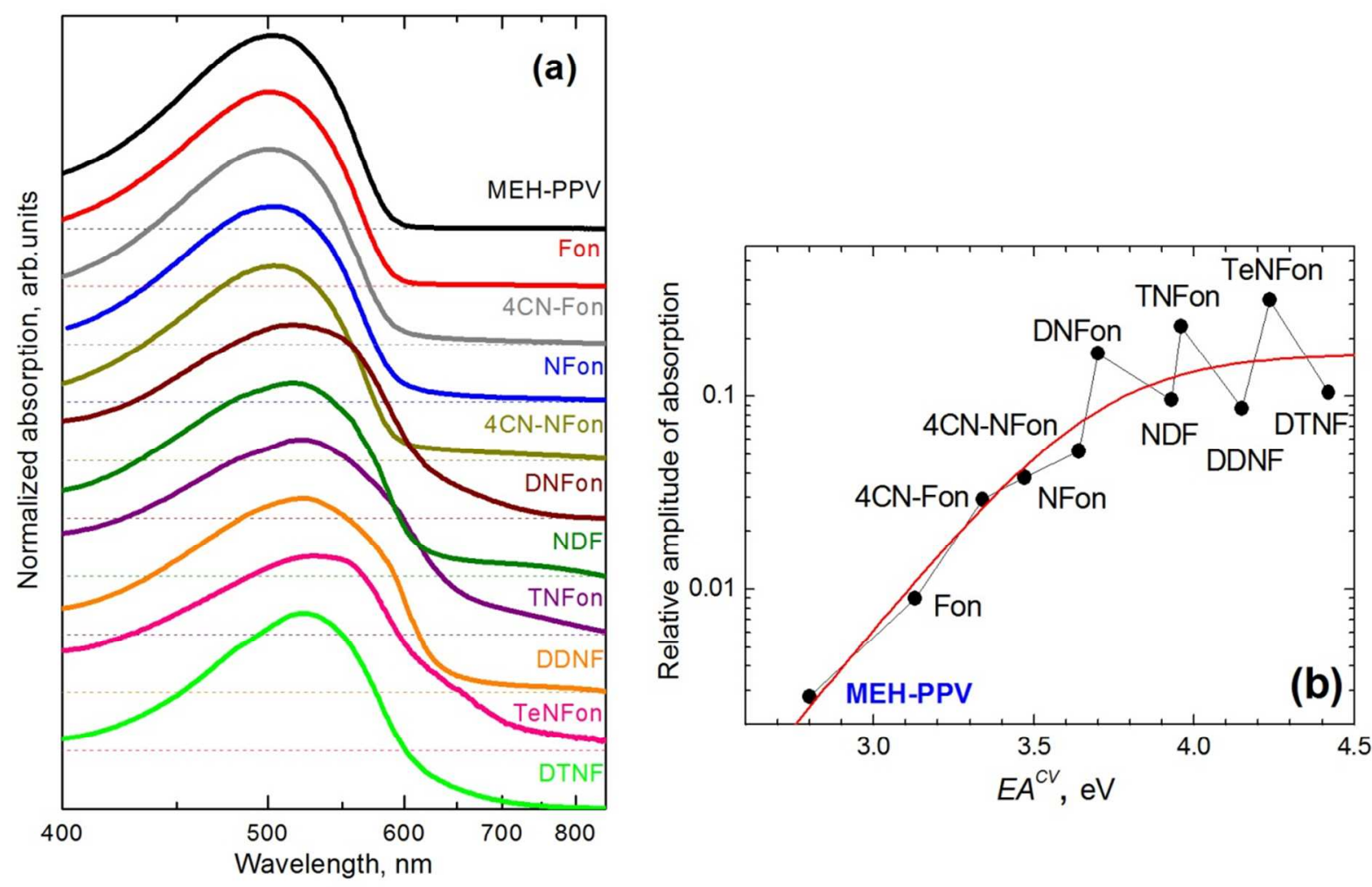

Figure 6. (a) Normalized absorption spectra for MEH-PPV:acceptor films. The spectra are shifted vertically for clarity; the acceptor EA increases from top to bottom. The spectrum of a pristine MEHPPV film is also shown at the top for comparison. (b) Absorption at the red tail of the spectrum (650 $\mathrm{nm}$; chosen arbitrarily) relatively to the maximum absorption as a function of acceptor EA. The red curve shows the fit to an $a d$ hoc function $A(\exp (-b \cdot E A)+c)^{-1}$ to highlight the initial exponential growth followed by the saturation.

The absorption spectra in Figure 6a indicate that the polymer forms easily observable CTCs with the acceptors having an EA equal or higher than that for DNFon. For acceptors with a relatively low EA (4CN-NFon, NFon, 4CN-Fon and Fon) the only CTC signature is a weak absorption in the polymer gap (Figure 6b) that increases exponentially with acceptor EA. Interestingly, the CTC absorption ceases to be a monotonic function of EA at the position of DNFon. As follows from Figure 6b, the fluorenone acceptors (i.e. with carbonyl oxygen at the C-9 bridged atom of the fluorene moiety, Figure 
1) form stronger absorbing CTCs than their dicyanomethylenefluorene-derivatized counterparts with comparable EAs (cf. for pairs NDF/TNFon and DDNF/TeNFon). Therefore, EA is not the only variable that governs the CTC properties even for acceptors with similar molecular structure.

\subsection{Photoinduced Charge Generation and Recombination}

While absorption data are indispensable in studying formation of the ground-state CTCs, they do not provide any information on the excited-state dynamics, i.e. on the processes of charge separation and recombination. For this, a visible-pump IR-probe arrangement ${ }^{20}$ was used where the magnitude of PIA signals in the region of LE polaron absorption (at $2.94 \mu \mathrm{m}$ ) monitors the concentration of photoinduced charges on the polymer.

Figure 7 shows isotropic PIA transients for all the MEH-PPV:acceptor blends recorded at an excitation wavelength of $560 \mathrm{~nm}$. This excitation wavelength was chosen at the lower-energy side of the absorption spectra (Figure 6a) to minimize deposition of excessive excitation energy. As is clear from Figure $7 \mathrm{a}$, the initial charge photogeneration for all the samples is extremely fast and occurs within the apparatus time resolution of $\sim 100 \mathrm{fs}$, regardless of the acceptor. Therefore, we conclude that the polaron generation in the blends occurs faster than $100 \mathrm{fs}$, and hence forward donor-to-acceptor electron transfer is almost immediate upon optical excitation and does not depend on the driving force for charge separation (acceptor EA). In contrast, the decaying parts of the transients are strongly acceptor-dependent with the relaxation timescale changing from $\sim 50$ ps for Fon to $\sim 1$ ps for DTNF. These timescales are attributed to the charge recombination (or back electron transfer from the acceptor to the polymer) process.

We briefly comment on the origin of the PIA signal from the film of pristine MEH-PPV. Ideally, such excitation should be of entirely excitonic nature so that no polarons are produced. However, a number of MEH-PPV excitons quickly dissociate into charge species which assignment was actively 
debated in the past (see for instance Ref. 66. Here we use the PIA signal from the pristine MEH-PPV film only as a reference for the charge recombination in the blends not affected by CTC formation.
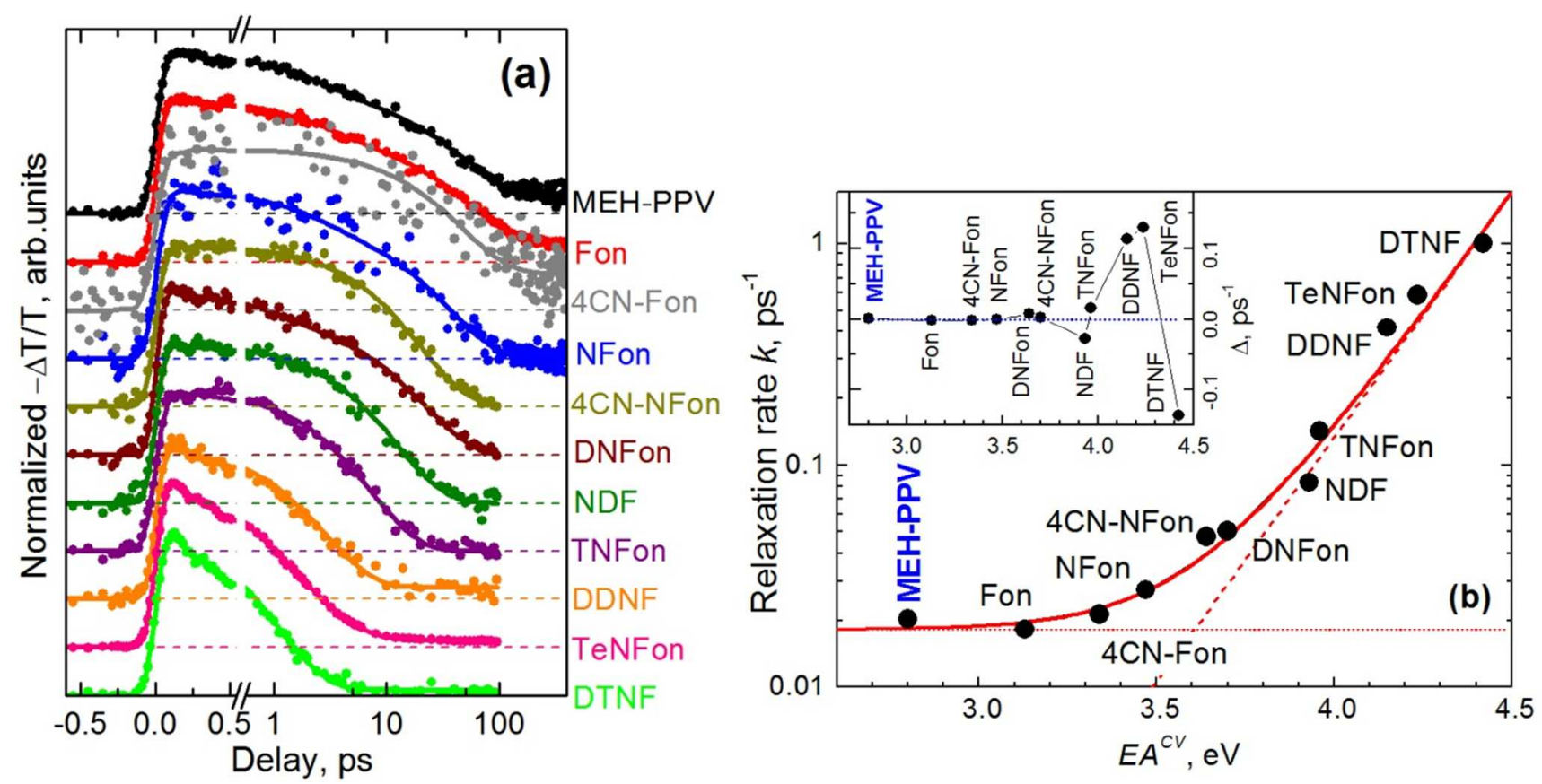

Figure 7. (a) Normalized isotropic PIA transients for the MEH-PPV:acceptor blends at an excitation wavelength of $560 \mathrm{~nm}$ and probe wavelength of $2.94 \mu \mathrm{m}$. Dots represent experimental data while solid curves show bi-exponential fits with the parameters listed in Table S3 in the Supporting Information. The transients are shifted vertically for clarity; the corresponding zero signal levels are shown by dashed lines. Note the logarithmic scaling of the delay axis after the break. The PIA signal from the pristine MEH-PPV film (black) is shown as a reference. (b) Charge recombination rate in blends of MEH-PPV:acceptor as a function of EA. The solid curve represents the best fit to the experimental data (dots) according to Eq.6. The dashed and dotted lines are asymptotes for the acceptor-to-polymer and intrapolymer recombination channels, respectively. The inset presents deviations of the experimental values from the best fit at the linear scale. 
To quantify the dynamics, the transients were fitted by a bi-exponential function (Figure 7a, solid lines) with fit parameters presented in Table S3 (see Supporting Information). Two recombination rates most probably correspond to different donor-acceptor configurations or/and partial electron transfer. In any case, for the majority of the acceptors, the amplitude of the dominating exponential functions exceeds $90 \%$ and is always higher than $80 \%$. We took the weighted average of the two time constants as the characteristic time of the charge recombination.

Figure $7 \mathrm{~b}$ summarizes the relation between the charge recombination rate, $k$, and the acceptor EA. The intermolecular recombination rate mostly follows the exponential trend with some deviations for low-EA acceptors. This deviation originates from a second, intrapolymer (i.e. between units of the same and/or different polymer chains) channel of charge recombination that is characteristic for pristine MEH-PPV. The charge recombination rate that accounts for the both donor-acceptor and intrapolymer channels is therefore expressed as follows:

$k=k_{E T} \cdot\left[\exp \left(\frac{E A}{\Delta E}\right)-1\right]+k_{0}$,

where $k_{E T}$ is the proportionality coefficient, $\Delta E$ is a characteristic energy, and $k_{0}$ is the rate of the intrapolymer charge recombination. The fit to the experimental data resulted in the following values: $k_{E T}=2.1 \cdot 10^{-10} \mathrm{ps}^{-1}, \Delta E=0.2 \mathrm{eV}$, and $k_{0}=0.018 \mathrm{ps}^{-1}$.

The linear dependence of the logarithm of the charge recombination rate, $\ln (k)$, on EA has been observed in many small-molecule ground-state CTCs, both in solution ${ }^{6,7}$ and solid phase. ${ }^{26,67}$ The obtained value of $\Delta E^{-1}=5 \mathrm{eV}^{-1}$ of the slope of the exponential factor is also similar to previous studies of small-molecule CTCs. For instance, Gould et al. ${ }^{6}$ reported the slope value of $\sim 5 \mathrm{eV}^{-1}$ in a series of CTCs formed between cyanoaromatic acceptors and methyl-substituted benzene donors. Hubig et al. found ${ }^{7,26}$ the slope to vary from $2 \mathrm{eV}^{-1}$ in benzene-methylviologen mixtures up to $3.6 \mathrm{eV}^{-1}$ in CTCs between large aromatics and TCNB (tetracyanobenzene) acceptor. 
In the Marcus model, ${ }^{68}$ an increase of the charge recombination rate with increasing EA (the driving force) corresponds to the so-called inverted regime. ${ }^{69-71}$ Various interpretations of the Marcus model were proposed to obtain a linear dependence of the experimentally observed $\ln (k)$ on EA for charge recombination in various small-molecule CTCs. As follows from the Marcus equation, ${ }^{68}$ such linear dependence of $\ln (k)$ appears when the reorganization energy becomes much larger than the driving force for charge recombination. As the latter is always higher than $0.5 \mathrm{eV}$ for the examined CTCs, this leads in our case to unreasonably high reorganization energy, by a factor of 5 higher than imposed by $k T$. On the other hand, the linear EA dependence of $\ln (k)$ can be assigned to the energy gap law for radiationless transitions in polyatomic molecules as was explained for small-molecule CTCs adsorbed on porous glass at different temperatures. ${ }^{67}$ These are quantum transitions between (nearly) degenerated vibrational levels that belong to the ground and excited electronic states of the molecule ${ }^{72}$ (that is a photoexcited CTC in our case). Note that these transitions are not thermally activated as the classic Marcus model implies (for detailed discussion of the inverted Marcus and the energy gap models, see Refs. $\left.{ }^{69,70}\right)$.Therefore, we suggest that in the conjugated polymer CTCs the charge recombination mechanism is very similar to that observed earlier in small-molecule CTCs.

The data in Figure 7a suggest that the acceptor EA is the prime factor that governs charge recombination rate for the CTCs used herein. Nonetheless, the fluorenone acceptors are characterized by slightly higher relaxation rates than the dicyanomethylenefluorene ones of similar EAs (compare, for instance, pairs of NDF/TNFon and DDNF/TeNFon). This shows that other CTC parameters such as the molecular orbital overlap, the donor-acceptor distances, packing motif etc. that enter the preexponential factor in Eq. 6, are also important.

From Figure $7 \mathrm{~b}$ one can readily establish the EA (which is, in the first approximation, directly linked to the driving force for charge recombination) where the donor-acceptor recombination channel begins to dominate over the intrapolymer one ( $~ 50$ ps for pristine MEH-PPV). This energy can be estimated by equalizing the rates of donor-acceptor and intrapolymer charge transfer, i.e. as the abscissa of the 
crossing point between the dashed and dotted lines in Figure $6 \mathrm{~b}$, which results in $\sim 3.6 \mathrm{eV}$. Figure 8 presents PIA anisotropy transients for the MEH-PPV:acceptor blends. The initial anisotropy value of $\sim 0.3$ is virtually independent of the acceptor. This means that the transient dipoles of photoexcitation (i.e. blend absorption) and probe (i.e. polaron absorption) remain unaffected by CTC formation. The long-time behavior strongly depends on the acceptor: for DNFon and acceptors with higher EA the transient anisotropy does not change appreciably from its initial value. In contrast, for the acceptors with lower EA (Fon, NFon, and 4CN-NFon), the anisotropy decreases with time in a similar fashion as for MEH-PPV, although to a lower extent. The anisotropy dynamics are ascribed to polaron migration on the polymer: as the polaron samples polymer segments with various orientations, the memory of the initial direction of the polaron transition dipole moment is more and more lost. Therefore, we conclude that the polarons are more mobile in the blends with acceptors of low EA, while they are more localized in the blends with the acceptors of higher EA. The border line, as found above in the isotropic PIA and steady-state spectroscopy data, is drawn at EA of the DNFon acceptor.

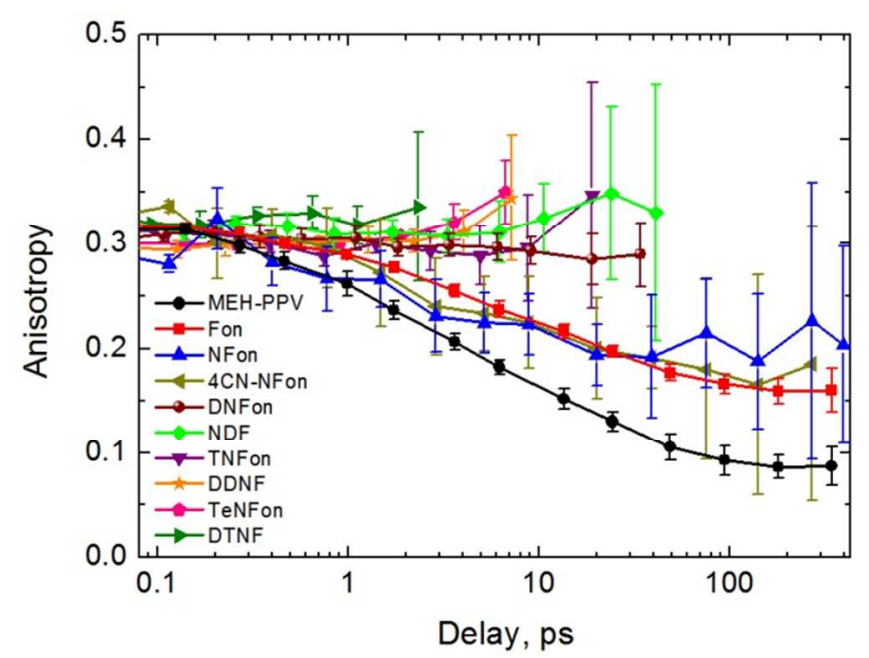

Figure 8. PIA anisotropy transients for the MEH-PPV:acceptor blends at an excitation wavelength of $560 \mathrm{~nm}$ and probe wavelength of $2.94 \mu \mathrm{m}$. The transients are delay-limited because of deteriorating signal-to-noise ratio due to short lifetimes in the blends with high-EA acceptors. 
Based on our optical experiments, we propose the following model of charge dynamics in polymeracceptor blends with ground-state CTCs (Figure 9). For low-EA acceptors, namely Fon, NFon, and 4CN-NFon, the CTC concentration in the polymer phase is relatively low while the majority of acceptor molecules form their own phase (Figure 9a). As a consequence, a part of the photoexcitations that are characteristic of pristine polymer is mobile, but another part - those of CTCs - is localized. The fraction of the former decreases for acceptors with high EA which results in the red-wing absorption (Figure 6a), accelerated recombination rate (Figure 7), and lowered anisotropy values (Figure 8). Acceptors with high EA form CTCs that are more dispersed in the conjugated polymer (Figure 9b; see also discussion on the absorption spectra, Figure 6) so that a polymer photoexcitation always occur near an acceptor molecule that immediately receives the photoexcited electron. Such complexation, in turn, planarizes MEH-PPV segments thereby increasing the conjugation length within these fragments of the polymer backbone (and consequently delocalization of the photoexcitation) that in turn facilitates an efficient charge separation processes. As a consequence, the polaron stays in the vicinity of its birth place which results in a time-independent anisotropy. Note that in this case the intrapolymer recombination channel (the second term in Eq. 6) becomes irrelevant and therefore the recombination rates approach the exponential behavior (Figure 7b). Most probably, the previously observed self-organization of the polymer chains in crystalline domains due to the CTC formation ${ }^{14}$ adds another dimension to this scenario; a more detailed investigation on this issue is underway. 


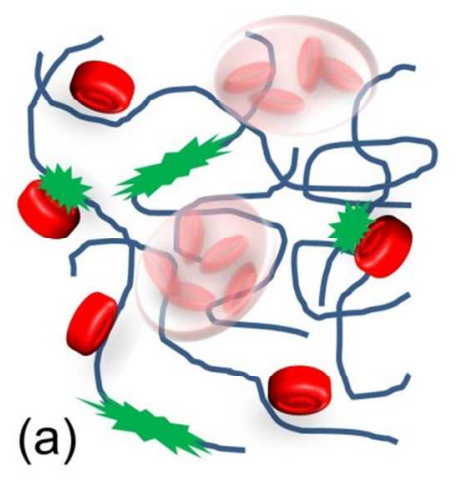

(b)

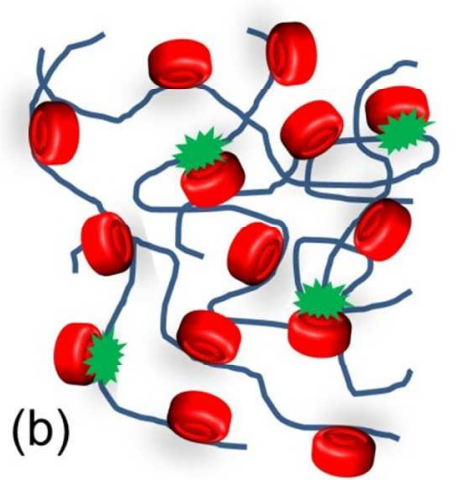

Figure 9. Impression of the MEH-PPV:acceptor blend charge dynamics for acceptors with low (a) and high (b) EAs. Very few of low-EA acceptors form CTCs (red pucks) with polymer chains (blue) while most of acceptors aggregate in their own phase (shadowed in light red). This results in mobile (extended green) and more localized (green) photoexcitations. In contrast, almost all high-EA acceptors form CTCs with polymer chains resulting in localized excitations only.

\section{CONCLUSIONS}

The ground-state CTCs formed between the MEH-PPV conjugated polymer donor and a series of fluorene electron acceptors with varying electron affinity have been studied using a combined platform of synthetic chemistry, DFT calculations, and time-resolved spectroscopy. The acceptor EAs were engineered by attaching a variety of electron withdrawing functional groups (cyano, nitro, and carbonyl) to the fluorene core to systematically modify the LUMO-HOMO energies of the acceptors. Both energies were calculated using a DFT method at the B3LYP/6-31+G(d) level of theory and compared with measurements of acceptor's electrochemical reduction potential obtained from cyclic voltammetry. The experimental and theoretical values demonstrated excellent agreement.

The formation of the ground-state CTCs in polymer-acceptor blends has been identified by optical absorption spectroscopy through the appearance of an additional absorption in the polymer bandgap. 
Visible-IR PIA spectroscopy has been further employed to study excited-state charge separation and recombination dynamics. In all the blends, charge photogeneration is extremely fast $(<100$ fs $)$, while charge recombination shows noticeably different dynamics ranging from 1 to 50 ps. The acceptor-topolymer recombination rates exhibit an exponential scaling with the acceptor EA with parameters that are similar to those reported earlier for small-molecule CTCs. Transient anisotropy data have indicated that in the CTCs with acceptors of relatively high EA, the mutual orientation of photoexcited and polaron transient dipole moments is retained, whereas in the low EA acceptors the two dipole moments become less correlated.

The experimental data have been discussed in terms of a charge dynamics model where the low EA acceptors form relatively sparse CTCs with the polymer chain and most of the acceptor molecules stay phase-separated from the polymer. In contrast, the high EA acceptors are thought to be rather dispersed in the polymer due to pronounced CTC formation. As a result, in the first case photoexcitations are fractioned between delocalized polymeric and more localized CTCs ones while in the second case photoexcitations are localized around the point of their creation.

The effect on the acceptor EA on the charge recombination dynamics has clear implications for organic solar cells. The charge-transfer state with the hole at the donor and the electron at the acceptor, both near the interface, has been recognized as a key intermediate state on the route from photon absorption to free charges in various donor-acceptor combinations. ${ }^{27,31,42,73}$ Our results demonstrate that acceptors with a higher EA (i.e. those providing a stronger driving force for charge separation) result in an exponentially increased recombination rate from the CTC state which leads to reduction of the longlived separated charges. These two opposite trends should be carefully balanced in designing the novel organic bulk heterojunctions. 


\section{ASSOCIATED CONTENT}

\section{Supporting Information}

Synthesis and characterization of studied fluorene acceptors with respective $1 \mathrm{H}$ and $13 \mathrm{C}$ NMR spectra, UV-visible absorption spectra of the acceptors, DFT calculations for fluorene acceptors and correlations between computational DFT data and CV experiments, fitting parameters for the ultrafast spectroscopy data.

This material is available free of charge via the Internet at http://pubs.acs.org.

\section{AUTHOR INFORMATION}

\section{Corresponding Authors}

*E-mail: M.S.Pchenitchnikov@rug.nl (MSP), i.perepichka@bangor.ac.uk (IFP)

+ Current address: Merck Chemicals Ltd., Chilworth Technical Centre, University Parkway, Southampton, SO16 7QD, UK

${ }^{\#}$ Current address: II. Physikalisches Institut, University of Cologne, 50923 Köln, Germany

\section{Notes}

The authors declare no competing financial interest.

\section{Author Contributions}

The manuscript was written through contributions of all authors. All authors have given approval to the final version of the manuscript. 


\section{Funding Sources}

ODP and DYuP acknowledge the partial support of Russian Foundation for Basic Research (RFBR \#13-03-12472 and \#13-02-01313) and the M. V. Lomonosov Moscow State University Program of Development.

\section{ACKNOWLEDGEMENTS}

We thank A. Serbenta for performing some measurements on optical absorption and ultrafast dynamics. A. A. Bakulin and D. Beljonne are acknowledged for many useful discussions. 


\section{REFERENCES}

1. Mulliken, R. S., Structures of Complexes Formed by Halogen Molecules with Aromatic and with Oxygenated Solvents. J. Am. Chem. Soc. 1950, 72, 600-608.

2. Mulliken, R. S., Molecular Compounds and Their Spectra. II. J. Am. Chem. Soc. 1952, 74, 811824.

3. Veldman, D.; Meskers, S. C. J.; Janssen, R. A. J., The Energy of Charge-Transfer States in Electron Donor-Acceptor Blends: Insight into the Energy Losses in Organic Solar Cells. Adv. Funct. Mater. 2009, 19, 1939-1948.

4. Hwang, I. W.; Moses, D.; Heeger, A. J., Photoinduced Carrier Generation in P3HT/PCBM Bulk Heterojunction Materials. J. Phys. Chem. C 2008, 112, 4350-4354.

5. Veldman, D.; Ipek, O.; Meskers, S. C. J.; Sweelssen, J.; Koetse, M. M.; Veenstra, S. C.; Kroon, J. M.; van Bavel, S. S.; Loos, J.; Janssen, R. A. J., Compositional and Electric Field Dependence of the Dissociation of Charge Transfer Excitons in Alternating Polyfluorene Copolymer/Fullerene Blends. $J$. Am. Chem. Soc. 2008, 130, 7721-7735.

6. Gould, I. R.; Noukakis, D.; Gomezjahn, L.; Young, R. H.; Goodman, J. L.; Farid, S., Radiative and Nonradiative Electron-Transfer in Contact Radical-Ion Pairs. Chem. Phys. 1993, 176, 439-456.

7. Hubig, S. M.; Bockman, T. M.; Kochi, J. K., Optimized Electron Transfer in Charge-Transfer Ion Pairs. Pronounced Inner-Sphere Behavior of Olefin Donors. J. Am. Chem. Soc. 1996, 118, 38423851.

8. Bakulin, A. A.; Elizarov, S. G.; Khodarev, A.; Martyanov, D. S.; Golovnin, I.; Paraschuk, D. Y.; Triebel, M. M.; Tolstov, I.; Frankevich, E. L.; Arnautov, S. A.; et al., Weak Charge-Transfer Complexes Based on Conjugated Polymers for Plastic Solar Cells. Synth. Met. 2004, 147, 221-225. 
9. Goris, L.; Haenen, K.; Nesladek, M.; Wagner, P.; Vanderzande, D.; De Schepper, L.; D'Haen, J.; Lutsen, L.; Manca, J. V., Absorption Phenomena in Organic Thin Films for Solar Cell Applications Investigated by Photothermal Deflection Spectroscopy. J. Mater. Sci. 2005, 40, 1413-1418.

10. Panda, P.; Veldman, D.; Sweelssen, J.; Bastiaansen, J. J. A. M.; Langeveld-Voss, B. M. W.; Meskers, S. C. J., Charge Transfer Absorption for $\pi$-Conjugated Polymers and Oligomers Mixed with Electron Acceptors. J. Phys. Chem. B 2007, 111, 5076-5081.

11. Wise, A. J.; Grey, J. K., Resonance Raman Studies of Excited State Structural Displacements of Conjugated Polymers in Donor/Acceptor Charge Transfer Complexes. Phys. Chem. Chem. Phys. 2012, $14,11273-11276$.

12. Sosorev, A. Y.; Paraschuk, D. Y., Charge-Transfer Complexes of Conjugated Polymers. Israel J. Chem. 2014, 54, 650-673.

13. Bruevich, V. V.; Makhmutov, T. S.; Elizarov, S. G.; Nechvolodova, E. M.; Paraschuk, D. Y., Raman Spectroscopy of Intermolecular Charge Transfer Complex between a Conjugated Polymer and an Organic Acceptor Molecule. J.Chem.Phys. 2007, 127, 104905-104909.

14. Parashchuk, O. D.; Grigorian, S.; Levin, E. E.; Bruevich, V. V.; Bukunov, K.; Golovnin, I. V.; Dittrich, T.; Dembo, K. A.; Volkov, V. V.; Paraschuk, D. Y., Acceptor-Enhanced Local Order in Conjugated Polymer Films. J. Phys. Chem. Lett. 2013, 4, 1298-1303.

15. Bruevich, V. V.; Makhmutov, T. S.; Elizarov, S. G.; Nechvolodova, E. M.; Paraschuk, D. Y., Ground State of $\pi$-Conjugated Polymer Chains Forming an Intermolecular Charge-Transfer Complex as Probed by Raman Spectroscopy. J. Exp. Theor. Phys. 2007, 105, 469-478.

16. Benson-Smith, J. J.; Goris, L.; Vandewal, K.; Haenen, K.; Manca, J. V.; Vanderzande, D.; Bradley, D. D. C.; Nelson, J., Formation of a Ground-State Charge-Transfer Complex in Polyfluorene/[6,6]-Phenyl-C-61 Butyric Acid Methyl Ester (PCBM) Blend Films and Its Role in the Function of Polymer/PCBM Solar Cells. Adv. Funct. Mater. 2007, 17, 451-457. 
17. Drori, T.; Sheng, C. X.; Ndobe, A.; Singh, S.; Holt, J.; Vardeny, Z. V., Below-Gap Excitation of $\pi$-Conjugated Polymer-Fullerene Blends: Implications for Bulk Organic Heterojunction Solar Cells. Phys. Rev. Lett. 2008, 101, 037401.

18. Goris, L.; Poruba, A.; Hodyakova, L.; Vanecek, M.; Haenen, K.; Nesladek, M.; Wagner, P.; Vanderzande, D.; De Schepper, L.; Manca, J. V., Observation of the Subgap Optical Absorption in Polymer-Fullerene Blend Solar Cells. Appl. Phys. Lett. 2006, 88, 052113.

19. Hallermann, M.; Haneder, S.; Da Como, E., Charge-Transfer States in Conjugated Polymer/Fullerene Blends: Below-Gap Weakly Bound Excitons for Polymer Photovoltaics. Appl. Phys. Lett. 2008, 93, 053307.

20. Bakulin, A. A.; Martyanov, D. S.; Paraschuk, D. Y.; Pshenichnikov, M. S.; van Loosdrecht, P. H. M., Ultrafast Charge Photogeneration Dynamics in Ground-State Charge-Transfer Complexes Based on Conjugated Polymers. J. Phys. Chem. B 2008, 112, 13730-13737.

21. Bakulin, A. A.; Martyanov, D.; Paraschuk, D. Y.; Loosdrecht, P. H. M. v.; Pshenichnikov, M. S., Charge-Transfer Complexes of Conjugated Polymers as Intermediates in Charge Photogeneration for Organic Photovoltaics. Chem. Phys. Lett. 2009, 482, 99-104.

22. He, Z.; Zhong, C.; Su, S.; Xu, M.; Wu, H.; Cao, Y., Enhanced Power-Conversion Efficiency in Polymer Solar Cells Using an Inverted Device Structure. Nat. Photon. 2012, 6, 591-595.

23. Liang, Y.; Xu, Z.; Xia, J.; Tsai, S.-T.; Wu, Y.; Li, G.; Ray, C.; Yu, L., For the Bright FutureBulk Heterojunction Polymer Solar Cells with Power Conversion Efficiency of 7.4\%. Adv. Mater. 2010, 22, 135-138.

24. van Mullekom, H. A. M.; Vekemans, J. A. J. M.; Havinga, E. E.; Meijer, E. W., Developments in the Chemistry and Band Gap Engineering of Donor-Acceptor Substituted Conjugated Polymers. Mat. Sci. Eng. R. 2001, 32, 1-40.

25. Blayney, A. J.; Perepichka, I. F.; Wudl, F.; Perepichka, D. F., Advances and Challenges in the Synthesis of Poly(P-Phenylene Vinylene)-Based Polymers. Israel J. Chem. 2014, 54, 674-688. 
26. Hubig, S. M.; Kochi, J. K., Photoinduced Electron Transfer in Charge-Transfer Crystals by Diffuse-Reflectance (Picosecond) Time-Resolved Spectroscopy. J. Phys. Chem. 1995, 99, 1757817585.

27. Deibel, C.; Strobel, T.; Dyakonov, V., Role of the Charge Transfer State in Organic DonorAcceptor Solar Cells. Adv. Mater. 2010, 22, 4097-4111.

28. Elizarov, S. G.; Ozimova, A. E.; Paraschuk, D. Y.; Arnautov, S. A.; Nechvolodova, E. M. In Laser Light Scattering as a Probe of Phase Separation in Conjugated Polymer Films of Donor-Acceptor Blends., ICONO 2005: Nonlinear Laser Spectroscopy, High Precision Measurements, and Laser Biomedicine and Chemistry, Proceedings of the Society of Photo-Optical Instrumentation Engineers (SPIE), 2006, 293-302.

29. Pommerehne, J.; Vestweber, H.; Guss, W.; Mahrt, R. F.; Bassler, H.; Porsch, M.; Daub, J., Efficient 2-Layer Leds on a Polymer Blend Basis. Adv. Mater. 1995, 7, 551-554.

30. Cardona, C. M.; Li, W.; Kaifer, A. E.; Stockdale, D.; Bazan, G. C., Electrochemical Considerations for Determining Absolute Frontier Orbital Energy Levels of Conjugated Polymers for Solar Cell Applications. Adv. Mater. 2011, 23, 2367-2371.

31. Brabec, C. J.; Sariciftci, N. S.; Hummelen, J. C., Plastic Solar Cells. Adv. Funct. Mater. 2001, $11,15-26$.

32. Frisch, M. J. T.; Schlegel, H. B.; Scuseria, G. E.; Robb, M. A.; Cheeseman, J. R.; Scalmani, G.; Barone, V.; Mennucci, B.; Petersson, G. A.; Nakatsuji, H.; et al., Gaussian 09, Revision A02; Gaussian, Inc.: Wallingford CT, 2009.

33. Becke, A. D., Density-Functional Exchange-Energy Approximation with Correct AsymptoticBehavior. Phys. Rev. A 1988, 38, 3098-3100.

34. Becke, A. D., Density-Functional Thermochemistry: 3. The Role of Exact Exchange. J. Chem. Phys. 1993, 98, 5648-5652. 
35. Lee, C. T.; Yang, W. T.; Parr, R. G., Development of the Colle-Salvetti Correlation-Energy Formula into a Functional of the Electron-Density. Phys. Rev. B 1988, 37, 785-789.

36. Barone, V.; Cossi, M.; Tomasi, J., A New Definition of Cavities for the Computation of Solvation Free Energies by the Polarizable Continuum Model. J. Chem. Phys. 1997, 107, 3210-3221.

37. Cammi, R.; Tomasi, J., Analytical Derivatives for Molecular Solutes: 1. Hartree-Fock Energy First Derivatives with Respect to External Parameters in the Polarizable Continuum Model. J. Chem. Phys. 1994, 100, 7495-7502.

38. Miertus, S.; Scrocco, E.; Tomasi, J., Electrostatic Interaction of a Solute with a Continuum - a Direct Utilization of Abinitio Molecular Potentials for the Prevision of Solvent Effects. Chem. Phys. 1981, 55, 117-129.

39. Tomasi, J.; Persico, M., Molecular-Interactions in Solution - an Overview of Methods Based on Continuous Distributions of the Solvent. Chem. Rev. 1994, 94, 2027-2094.

40. Tomasi, J.; Mennucci, B.; Cammi, R., Quantum Mechanical Continuum Solvation Models. Chem Rev. 2005, 105, 2999-3093.

41. Mizrahi, U.; Shtrichman, I.; Gershoni, D.; Ehrenfreund, E.; Vardeny, Z. V., Picoseconds Time Resolved Photoinduced Absorption by Infrared Active Vibrations as a Probe for Charge Photogeneration in MEH-PPV/C-60 Composites. Synth. Met. 1999, 102, 1182-1185.

42. Sariciftci, N. S.; Smilowitz, L.; Heeger, A. J.; Wudl, F., Photoinduced Electron-Transfer from a Conducting Polymer to Buckminsterfullerene. Science 1992, 258, 1474-1476.

43. Lane, P. A.; Wei, X.; Vardeny, Z. V., Studies of Charged Excitations in $\pi$-Conjugated Oligomers and Polymers by Optical Modulation. Phys. Rev. Lett. 1996, 77, 1544-1547.

44. Osterbacka, R.; Wohlgenannt, M.; Shkunov, M.; Chinn, D.; Vardeny, Z. V., Excitons, Polarons, and Laser Action in Poly(P-Phenylene Vinylene) Films. J. Chem. Phys. 2003, 118, 8905-8916.

45. Gordon, R. G., Molecular Collisions and Depolarization of Fluorescence in Gases. J. Chem. Phys. 1966, 45, 1643-1655. 
46. Mysyk, D. D.; Perepichka, I. F.; Perepichka, D. F.; Bryce, M. R.; Popov, A. F.; Goldenberg, L. M.; Moore, A. J., Electron Accepters of the Fluorene Series. 9. Derivatives of 9-(1,2-Dithiol-3Ylidene)-, 9-(1,3-Dithiol-2-Ylidene)-, and 9-(1,3-Selenathiol-2-Ylidene)Fluorenes: Synthesis, Intramolecular Charge Transfer, and Redox Properties. J.Org. Chem. 1999, 64, 6937-6950.

47. Mysyk, D. D.; Perepichka, I. F.; Sokolov, N. I., Electron Acceptors of the Fluorene Series .6. Synthesis of 4,5-Dinitro-9-X-Fluorene-2,7-Disulfonic Acid Derivatives, Their Charge Transfer Complexes with Anthracene and Sensitization of Photoconductivity of Poly-N-(2,3Epoxypropyl)Carbazole. J. Chem. Soc. Perkin Trans. 2 1997, 537-545.

48. Perepichka, D. F.; Bryce, M. R.; Perepichka, I. F.; Lyubchik, S. B.; Christensen, C. A.; Godbert, N.; Batsanov, A. S.; Levillain, E.; McInnes, E. J. L.; Zhao, J. P., A (Pi-Extended Tetrathiafulvalene)Fluorene Conjugate. Unusual Electrochemistry and Charge Transfer Properties: The First Observation of a Covalent D2+-Sigma-a(Center Dot-) Redox State. J. Am. Chem. Soc. 2002, 124, 14227-14238.

49. Perepichka, I. F., Multiphoton and Light Driven Multielectron Processes in Organics: Materials, Phenomena, Applications, . In Nato Science Series: 3. High Technology Kajzar, F. A. M. V., Ed. Kluwer Academic Publishers: Dordrecht, 2000; 79, 371-386.

50. Perepichka, I. F.; Kuz'mina, L. G.; Perepichka, D. F.; Bryce, M. R.; Goldenberg, L. M.; Popov, A. F.; Howard, J. A. K., Electron Acceptors of the Fluorene Series. 7 2,7-Dicyano-4,5-Dinitro-9-XFluorenes: Synthesis, Cyclic Voltammetry, Charge Transfer Complexation with N-Propylcarbazole in Solution, and X-Ray Crystal Structures of Two Tetrathiafulvalene Complexes. J. Org. Chem. 1998, 63, 6484-6493.

51. Perepichka, I. F.; Popov, A. F.; Orekhova, T. V.; Bryce, M. R.; Andrievskii, A. M.; Batsanov, A. S.; Howard, J. A.; Sokolov, N. I., Electron Acceptors of the Fluorene Series. 10. Novel Acceptors Containing Butylsulfanyl, Butylsulfinyl, and Butylsulfonyl Substituents: Synthesis, Cyclic Voltammetry, Charge-Transfer Complexation with Anthracene in Solution, and X-Ray Crystal Structures of Two Tetrathiafulvalene Complexes. J. Org. Chem. 2000, 65, 3053-3063. 
52. Perepichka, I. F.; Popov, A. F.; Orekhova, T. V.; Bryce, M. R.; Vdovichenko, A. N.; Batsanov, A. S.; Goldenberg, L. M.; Howard, J. A. K.; Sokolov, N. I.; Megson, J. L., Electron Acceptors of the Fluorene Series. Part 5. Intramolecular Charge Transfer in Nitro-Substituted 9(Aminomethylene)fluorenes. J. Chem. Soc. Perkin Trans. 2 1996, 2453-2469.

53. Perepichka, D. F.; Perepichka, I. F.; Ivasenko, O.; Moore, A. J.; Bryce, M. R.; Kuz'mina, L. G.; Batsanov, A. S.; Sokolov, N. I., Combining High Electron Affinity and Intramolecular Charge Transfer in 1,3-Dithiole-Nitrofluorene Push-Pull Diads. Chem. Eur. J. 2008, 14, 2757-2770.

54. Perepichka, D. F.; Perepichka, I. F.; Popov, A. F.; Bryce, M. R.; Batsanov, A. S.; Chesney, A.; Howard, J. A. K.; Sokolov, N. I., Electron Acceptors of the Fluorene Series. Part 12. 9(Metalloceneylidene)nitrofluorene Derivatives of FC-NF, NF-FC-NF, and NF-RC-NF Types, and the

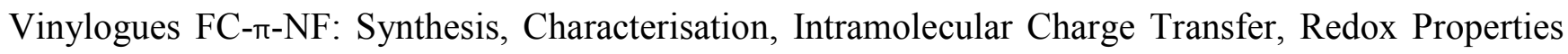
and X-Ray Structures for Three Fluorene-Ferrocene Derivatives. J. Organomet. Chem. 2001, 637, 445462.

55. Perepichka, I. F.; Perepichka, D. F.; Lyubchik, S. B.; Bryce, M. R.; Batsanov, A. S.; Howard, J. A. K., Electron Acceptors of the Fluorene Series. Part 13. 9-(5-Nitrofuran-2-Ylidene)- and 9-(5-Nitro2-Thienylidene)-2,4,5,7-Tetranitrofluorenes: Novel $\pi$-Extended Electron Acceptors. Synthesis, Cyclic Voltammetry and X-Ray Crystal Structures for the Acceptor and Its 4,5-Dimethyltetrathiafulvalene Complex, and a Theoretical Study. J. Chem. Soc. Perkin Trans. 2 2001, 1546-1551.

56. Batsanov, A. S.; Perepichka, I. F.; Bryce, M. R.; Howard, J. A. K., Cocrystals of 2-(2,4,5,7Tetranitrofluoren-9-Ylidene)Propanedinitrile and 2,4,5,7-Tetranitrofluoren-9-One with Chlorobenzene. Acta Crystallogr. Sect. C 2001, 57, 1299-1302.

57. Kuz'mina, L. G.; Perepichka, I. F.; Perepichka, D. F.; Howard, J. A. K.; Bryce, M. R., Supramolecular Architecture of Two Charge-Transfer Complexes Based on 2,7-(X,X)-4,5-Dinitro-9dicyanomethylenefluorenes $\left(\mathrm{X}=\mathrm{NO}_{2}\right.$ or $\left.\mathrm{CN}\right)$ and Tetrathiafulvalene. Crystallogr. Rep. 2002, 47, 251261. 
58. Batsanov, A. S.; Bryce, M. R.; Lyubchik, S. B.; Perepichka, I. F., An Unexpected TTFAQ Donor-Fluorene Acceptor Reaction Resulting in a Novel Salt: 2,6-Dihexyloxy-9,10-bis(4,5-dimethyl1,3-dithiol-2-ylium)-anthracene bis(2,5,7-Trinitro-4-bromo-9-cyanofluorenide) Dioxane Trisolvate. Acta Crystallogr. E 2002, 58, 1106-1110.

59. Batsanov, A. S.; Perepichka, I. F., 9-Dicyanomethylene-4,5-Dinitrofluorene-2,7-Disulfonamide. Acta Crystallogr. Sect. E 2004, 60, 1892-1894.

60. Semidetko, O. V.; Chetkina, L. A.; Belskii, V. K.; Mysyk, D. D.; Perepichka, I. F.; Andrievskii, A. M., Some Transformations and Structure of 2,5,7-Trinitro-4-Cyanofluorenone, C14H4N4O7. Zh. Obshch. Khim. 1987, 57, 415-420.

61. Körzdörfer, T.; Brèdas, J. L., Organic Electronic Materials: Recent Advances in the Dft Description of the Ground and Excited States Using Tuned Range-Separated Hybrid Functionals. Acc. Chem. Res. 2014.

62. Körzdörfer, T.; Sears, J. S.; Sutton, C.; Brèdas, J. L., Long-Range Corrected Hybrid Functionals for $\pi$-conjugated Systems: Dependence of the Range-Separation Parameter on Conjugation Length. $J$. Chem. Phys. 2011, 135, 204107.

63. Mori-Sanchez, P.; Cohen, A. J.; Yang, W., Many-Electron Self-Interaction Error in Approximate Density Functionals. J. Chem. Phys. 2006, 125, 201102.

64. Cohen, A. J.; Mori-Sanchez, P.; Yang, W., Insights into Current Limitations of Density Functional Theory. Science 2008, 321, 792-804.

65. Zhao, Y.; Truhlar, D. G., Density Functionals with Broad Applicability in Chemistry. Acc. Chem. Res. 2008, 41, 157-167.

66. Rothberg, L. J.; Yan, M.; Papadimitrakopoulos, F.; Galvin, M. E.; Kwock, E. W.; Miller, T. M., Photophysics of Phenylenevinylene Polymers. Synth. Met. 1996, 80, 41-58.

67. Miyasaka, H.; Kotani, S.; Itaya, A.; Schweitzer, G.; De Schryver, F. C.; Mataga, N., Temperature Effects on the Energy Gap Dependence of Charge Recombination Rates of Ion Pairs 
Produced by Excitation of Charge-Transfer Complexes Adsorbed on Porous Glass. J. Phys. Chem. B 1997, 101, 7978-7984.

68. Marcus, R. A., On the Theory of Oxidation-Reduction Reactions Involving Electron Transfer .1. J. Chem. Phys. 1956, 24, 966-978.

69. Suppan, P., The Marcus Inverted Region. In Photoinduced Electron Transfer IV, Mattay, J., Ed. Springer Berlin Heidelberg: 1992, 163, 95-130.

70. Kuzmin, M. G.; Soboleva, I. V.; Dolotova, E. V.; Dogadkin, D. N., The Nature of Internal Conversion and Intersystem Crossing in Exciplexes. High Energy Chem. 2005, 39, 86-96.

71. May, V.; Kuhn. O., Charge and Energy Transfer Dynamics in Molecular Systems,, 3rd ed.; Wiley-VCH: Weinheim, 2011.

72. Englman, R.; Jortner, J., Energy Gap Law for Radiationless Transitions in Large Molecules. Mol. Phys. 1970, 18, 145-164.

73. Bakulin, A. A.; Rao, A.; Pavelyev, V. G.; van Loosdrecht, P. H. M.; Pshenichnikov, M. S.; Niedzialek, D.; Cornil, J.; Beljonne, D.; Friend, R. H., The Role of Driving Energy and Delocalized States for Charge Separation in Organic Semiconductors. Science 2012, 335, 1340-1344. 
TOC figure

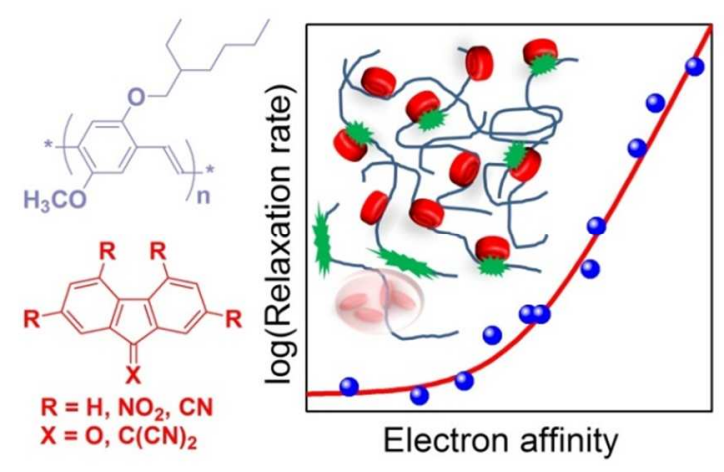

Acceptor electron affinity governs the charge recombination rate in polymer-acceptor blends

25

26

27

28

29

30

31

32

33

34

35

36

37

38

39

40

41

42

43

44

45

46

47

48

49

50

51

52

53

54

55

56

57

58

59

60 